\title{
COMMENTARY
}

\section{Is antithrombin treatment of disseminated intravascular coagulation a quixotic goal?}

\author{
Nitin Seam ${ }^{1,2}$ and Anthony F Suffredini ${ }^{2^{*}}$ \\ See related research by lba et al., http://ccforum.com/content/18/5/497
}

\begin{abstract}
The development of disseminated intravascular coagulation (DIC) is associated with increased sepsis mortality. Antithrombin (AT) is one of several anticoagulants that have been studied in randomized trials of sepsis without benefit. In a recent study, Iba and colleagues reviewed data from patients who were treated for sepsis-related DIC with two lower doses of AT concentrate than studied in prior trials. Patients received $1,500 \mathrm{IU} /$ day $(n=259)$ or $3,000 \mathrm{IU} /$ day $(n=48)$ of AT for 3 days. All patients had baseline antithrombin activity $<40 \%$ and there was no placebo group. The AT 3,000 group had higher 28-day survival as well as a higher rate of DIC resolution than the AT 1,500 group. Though intriguing, the study findings are limited by the non-randomized retrospective nature of the findings, which resulted in baseline differences in multiple confounders that affect mortality, as well as the lack of a placebo group to compare outcomes.
\end{abstract}

In a previous issue of Critical Care, Iba and colleagues describe the results of a post-marketing surveillance that compared the outcomes of 3 days of antithrombin (AT) concentrate dosed at either 3,000 or 1,500 IU/day in septic patients with disseminated intravascular coagulation (DIC) [1]. The higher dose, while lower than that used in many previous studies, improved survival and led to more prompt resolution of DIC. Their analysis raises several questions regarding the use of AT and the design of future trials in DIC.

DIC is a syndrome closely linked to the pathogenesis of organ failure in critical illness and is an independent

\footnotetext{
*Correspondence: asuffredini@cc.nih.gov

${ }^{2}$ Critical Care Medicine Department, Clinical Center, National Institutes of Health, Bethesda, MD 20892, USA

Full list of author information is available at the end of the article
}

predictor of organ failure and mortality in septic shock $[2,3]$. The diagnosis of DIC is based on clinical findings and established using scoring systems based on abnormalities of common tests (that is, platelet number, fibrinogen, fibrin markers, and prothrombin time). Higher DIC scores are strongly correlated with mortality [4]. Reconciling differences in guidelines from the United Kingdom, Italy and Japan for the diagnosis and therapy of DIC was recommended in a recent publication [5]. In actively bleeding patients with DIC, the cornerstone of therapy is treatment of the underlying condition and transfusion of blood products. In DIC where thrombosis predominates, heparin should be considered (low quality of evidence) [5]. The use of anticoagulant factor concentrates such as AT was 'potentially recommended' (low-degree recommendation) [5]. Current Japanese guidelines recommend AT supplementation as a standard of care for septic patients with DIC [6,7]. Until new data are available, the guidelines recommend that local consensus for therapy be followed [8].

Iba and colleagues describe a non-randomized survey of AT use in sepsis-associated DIC focusing on two potentially important factors, dose and baseline AT activity [1]. The doses studied were two- to four-fold lower than the doses described in many prior randomized trials of AT in sepsis-associated DIC [9]. Baseline AT activity in all patients was less than $40 \%$. Forty-eight patients were treated with 3,000 IU AT/day and 259 patients were given 1,500 IU AT/day, each for 3 days. The 3,000 IU dose resulted in better recovery from DIC and a $21 \%$ increase in 28-day survival (77.1 versus $56.4, P=0.01$ ).

A previous survey by the authors of 729 septic DIC patients focused on the same lower doses as the current survey but in patients with AT $<70 \%$. Mortality was not different between doses and the risk of severe bleeding was $<2 \%$ [10].

These data should be considered in the context of two prior meta-analyses. The first analyzed seven trials of 
AT in septic patients and found no clear benefit and no relationship between risk of death and any treatment effect of AT [11]. The later one analyzed 20 trials of 3,458 critically ill patients randomized to treatment with AT or placebo. AT therapy was either titrated to achieve normal levels or given at a fixed dose. Mortality was not improved with AT nor was it altered in a subgroup analysis of 2,601 septic patients [9].

In the largest single trial, high dose AT (30,000 IU total over 4 days) in 2,314 patients with severe sepsis did not improve 28-day survival [12]. A post hoc analysis suggested that patients who received AT without heparin had a survival benefit compared with placebo with no heparin [13]. The interaction of heparin and AT is important since the beneficial effect of AT in sepsis may relate to both potent anticoagulant and anti-inflammatory properties. The concurrent use of heparin may reduce AT efficacy by greatly enhancing anticoagulant effects (and risk of bleeding) while diminishing its anti-inflammatory properties [14].

The hypothesis of Iba and colleagues regarding the benefits of lower dose AT is confounded by several factors: baseline platelet counts, differences in the underlying sources of infection and the number of patients who underwent surgery, as well as imbalances between the groups regarding the severity of illness, the use of heparin and recombinant thrombomodulin [1]. No control group is available to assess the effects of standard therapy alone. The majority of patients given the lowest dose AT (1,500 IU/day for 3 days) did not normalize their levels of AT in contrast to patients given 3,000 IU/day. Data describing usual care for severe sepsis (for example, antibiotics, fluids, vasopressors) were not provided.

It is intriguing to consider whether lower-dose AT improves outcomes in severe sepsis without increasing bleeding. However, the limitations described above require that a large randomized controlled trial be conducted to determine whether this is useful in severe sepsis with DIC. Any future trial will need to account for differences in standards of practice for severe sepsis in different regions of the world $[15,16]$.

\section{Abbreviations \\ AT: Antithrombin; DIC: Disseminated intravascular coagulation.}

\section{Competing interests}

The authors declare that they have no competing interests.

\section{Acknowledgements}

Supported by the Department of Veterans Affairs, Washington DC and the Intramural Research Program of the Clinical Center, National Institutes of Health, Bethesda, MD.

\section{Author details}

${ }^{1}$ Pulmonary Section, Veterans Affairs Medical Center, Washington, DC 20442, USA. ${ }^{2}$ Critical Care Medicine Department, Clinical Center, National Institutes of Health, Bethesda, MD 20892, USA.

Published online: 25 November 2014

\section{References}

1. Iba T, Saitoh D, Wada H, Asakura H: Efficacy and bleeding risk of antithrombin supplementation in septic disseminated coagulation: a secondary survey. Crit Care 2014, 18:497.

2. Fourrier F, Chopin C, Goudemand J, Hendrycx S, Caron C, Rime A, Marey A, Lestavel P: Septic shock, multiple organ failure, and disseminated intravascular coagulation. Compared patterns of antithrombin III, protein C, and protein S deficiencies. Chest 1992, 101:816-823.

3. Dhainaut JF, Yan SB, Joyce DE, Pettila V, Basson B, Brandt JT, Sundin DP, Levi $M$ : Treatment effects of drotrecogin alfa (activated) in patients with severe sepsis with or without overt disseminated intravascular coagulation. J Thromb Haemost 2004, 2:1924-1933.

4. Toh $\mathrm{CH}$, Hoots WK: The scoring system of the Scientific and Standardisation Committee on Disseminated Intravascular Coagulation of the International Society on Thrombosis and Haemostasis: a 5-year overview. J Thromb Haemost 2007, 5:604-606.

5. Wada H, Thachil J, Di Nisio M, Mathew P, Kurosawa S, Gando S, Kim HK, Nielsen JD, Dempfle CE, Levi M, Toh CH, The Scientific Standardization Committee on DIC of the International Society on Thrombosis Haemostasis: Guidance for diagnosis and treatment of DIC from harmonization of the recommendations from three guidelines. J Thromb Haemost 2013, 10.1111/jth.12155.

6. Wada H, Asakura H, Okamoto K, Iba T, Uchiyama T, Kawasugi K, Koga S, Mayumi T, Koike K, Gando S, Kushimoto S, Seki Y, Madoiwa S, Maruyama I, Yoshioka A, Japanese Society of Thrombosis Hemostasis/DIC subcommittee: Expert consensus for the treatment of disseminated intravascular coagulation in Japan. Thromb Res 2010, 125:6-11.

7. Iba T: Harmonized guidance for disseminated intravascular coagulation from the International Society on Thrombosis and Haemostasis and the current status of anticoagulant therapy in Japan. J Thromb Haemost 2013, 11:2076-2078

8. Wada H, Thachil J, Di Nisio M, Kurosawa S, Gando S, Toh CH: Harmonized guidance for disseminated intravascular coagulation from the International Society on Thrombosis and Haemostasis and the current status of anticoagulant therapy in Japan: a rebuttal. $J$ Thromb Haemost 2013, 11:2078-2079.

9. Afshari A, Wetterslev J, Brok J, Moller AM: Antithrombin III for critically ill patients. Cochrane Database Syst Rev 2008, CD005370.

10. Iba T, Saito D, Wada H, Asakura H: Efficacy and bleeding risk of antithrombin supplementation in septic disseminated intravascular coagulation: a prospective multicenter survey. Thromb Res 2012, 130:e129-e133.

11. Minneci PC, Deans KJ, Cui X, Banks SM, Natanson C, Eichacker PQ: Antithrombotic therapies for sepsis: a need for more studies. Crit Care Med 2006, 34:538-541.

12. Warren BL, Eid A, Singer P, Pillay SS, Carl P, Novak I, Chalupa P, Atherstone A, Pénzes I, Kübler A, Knaub S, Keinecke HO, Heinrichs H, Schindel F, Juers M, Bone RC, Opal SM, KyberSept Trial Study Group: Caring for the critically ill patient. High-dose antithrombin III in severe sepsis: a randomized controlled trial. JAMA 2001, 286:1869-1878.

13. Kienast J, Juers M, Wiedermann CJ, Hoffmann JN, Ostermann H, Strauss R, Keinecke HO, Warren BL, Opal SM: Treatment effects of high-dose antithrombin without concomitant heparin in patients with severe sepsis with or without disseminated intravascular coagulation. J Thromb Haemost 2006, 4:90-97.

14. Opal SM, Kessler CM, Roemisch J, Knaub S: Antithrombin, heparin, and heparan sulfate. Crit Care Med 2002, 30(5 Suppl):S325-S331.

15. Kellum JA, Uchino S: International differences in the treatment of sepsis: are they justified? JAMA 2009, 301:2496-2497.

16. Iba T, Gando S, Thachil J: Anticoagulant therapy for sepsis-associated disseminated intravascular coagulation: the view from Japan. J Thromb Haemost 2014, 12:1010-1019.

doi:10.1186/s13054-014-0639-1

Cite this article as: Seam and Suffredini: Is antithrombin treatment of disseminated intravascular coagulation a quixotic goal? Critical Care 2014 18:639. 